\title{
Butterfly Diversity and Abundance in the Middle Afromontane Area of Northwestern Ethiopia
}

\author{
Melaku Wale ${ }^{1}{ }^{1}$ and Sofia Abdella ${ }^{2}$ \\ ${ }^{1}$ Bahir Dar University, P.O. Box 79, Bahir Dar, Ethiopia \\ ${ }^{2}$ Enfranz Secondary School, North Gondar, Ethiopia \\ Correspondence should be addressed to Melaku Wale; melakuwale@gmail.com
}

Received 27 April 2021; Accepted 19 August 2021; Published 2 September 2021

Academic Editor: Zeljko Tomanovic

Copyright (C 2021 Melaku Wale and Sofia Abdella. This is an open access article distributed under the Creative Commons Attribution License, which permits unrestricted use, distribution, and reproduction in any medium, provided the original work is properly cited.

\begin{abstract}
Butterflies are good indicators of environmental health, and they play a critical role in the food chain. Butterfly diversity and abundance were studied for the first time at three forests and their surrounding habitats in northwestern Ethiopia, a borderline ecosystem between the subtropical savannah and the Ethiopian highlands (Afromontane). Butterfly species richness and abundance were assessed using transects between October 2018 and June 2019. Data were analyzed using analysis of variance, correlation and regression analysis, diversity indices, ordination analysis, cluster analysis, and rarefaction curves. A total of 27,568 butterflies were recorded that belonged to three families, five subfamilies, and eight genera. The forest habitat had more butterfly taxa (abundance and diversity) than other habitats. Belenois spp. and Mylothris agathina were the most abundant in all three study locations. Species common to all study areas include Belenois aurota, Belenois raffrayi, Mylothris agathina, Eronia leda, Junonia terea elgiva, and Phalanta eurytis neuritis. Forest edge and woody forest habitats were the richest in terms of both number of species and number of individuals. Equitability (Pielou's index) showed equal distribution of the species, i.e., 0.8 to 0.9, except at the open grassland at Tara Gedam (0.3). Margalef's index varied between habitats and locations showing differences in species richness (from 0.25 at the woody forest of Mount Bezawit to 0.86 at the forest edge of Tara Gedam). Ordination analyses also showed that associations existed between habitats, locations, and dates of sampling. Rarefaction curves rose quickly at the forest edge and woody forest habitats compared to other forests. The cluster analysis discriminated the different habitats. Populations declined during the dry season (December to April). In conclusion, butterfly species diversity and abundance varied with respect to habitat and sampling date (season), although less diverse than other regions in the country where natural forests still widely exist. Butterfly species must be regularly monitored, and their habitats must be preserved for the health of the entire ecosystem.
\end{abstract}

\section{Introduction}

Landscape preservation is claimed to be a practical alternative to species-based approaches for the conservation of biological diversity [1]. To protect landscapes, they should first be effectively identified, evaluated, and characterized. This is no easy task, however, because landscape systems constantly change and can be defined in a number of scales $[2,3]$.

Insects are particularly useful indicators in the evaluation of landscapes for biological conservation $[4,5]$. Among the great diversity of insects, butterflies stand as ideal candidates for ecological study in landscapes $[6,7]$.
Generally, butterflies are represented by a diverse yet relatively small number of species in a wide spectrum of ecological settings. Butterflies quickly respond to environmental variation [8]. Positive relation has been reported between butterfly diversity and environmental variables. For example, they responded positively to plant diversity $[6,9-11]$, to habitat complexity [12], to landscape structure [13], to topographic and moisture gradients [14], and to climate [7]. The nature of landscapes, altitude, climate, and land use systems dictate species diversity and abundance. Inventory and monitoring of butterflies have been found useful when evaluating terrestrial landscapes for biological conservation [5]. Including them is of vital importance when one wants to 
assess and classify habitats $[7,15,16]$ and when evaluating the effects of land use and urbanization $[6,14,17,18]$. National Parks and other land management agencies are using butterflies in the evaluation and management of ecosystems [19]. Butterflies also offer aesthetic value and play great ecological significance as consumers and pollinators in the ecosystem [20] and as a major component of the food chain. Unfortunately, in tropical regions, especially in Ethiopia, butterfly taxonomy and natural history are hardly understood and most species are difficult to identify in the field. The present investigation was an attempt to investigate butterfly taxa of different forests and their surroundings (Tara Gedam, Alemsaga, and Mount Bezawit) in the borderline between the subtropical savannah grassland ecosystem and the Afromontane region of northwestern Ethiopia, an area lying east of Lake Tana, Ethiopia, and along the banks of the Blue Nile River.

\section{Materials and Methods}

2.1. Description of the Study Areas. This study was carried out in selected state forests, predominantly natural forests, i.e., Tara Gedam, Alemsaga, and Mount Bezawit, all found in the neighborhood of the area known as Lake Tana Biosphere Reserve, or Tana Basin, northwest Ethiopia (see Figure 1). The study area is a borderline between the tropical savanna climate, rather very close to the subtropical highland climate or the Afromontane. Afternoon temperatures are very warm to hot year round, and morning temperatures are cool; however, the diurnal range is much larger in the largely cloudless dry season. Grasslands and crop fields nearby were used as control. The forest and physical characteristics of the study areas were assessed in addition to other secondary data from published sources. Mount Bezawit forest is located in the southeastern fringes of the city of Bahir Dar, the capital of Amhara Region of Ethiopia. Bahir Dar, founded in the fourteenth century, lies at the shore of Lake Tana and the Blue Nile River [21]. The landscape is flat with some hills to the east (Mount Bezawit, itself a forest, where one of the Royal Palaces of Haile Selassie I is found at the center) and to the west (Dibanke Hills). Farta district, which encompasses Alemsaga Forest, is one of the districts in South Gondar zone, northwestern Ethiopia. The altitude of Farta varies from 1970 to $4135 \mathrm{~m}$. The area has an average annual minimum temperature of $9.3^{\circ} \mathrm{C}$, a maximum of $23.2^{\circ} \mathrm{C}$, and an annual average rainfall of $1448 \mathrm{~mm}$. Tara Gedam forest is located at the western edge of Addis Zemen town, Northeast of Lake Tana, northwestern Ethiopia. It is located in South Gondar zone of the Amhara Region, Ethiopia. Environmental physical details of the three forests, i.e., Tara Gedam, Alemsaga, and Mount Bezawit, are given in Table 1.

2.2. Study Design and Period. A quantitative study was carried out from October 2018 to June 2019 to determine the diversity of butterflies in the Tara Gedam, Alemsaga, and Mount Bezawit forests and surrounding habitats.
2.3. Sampling Methods. Butterflies were counted on strip transects as suggested by Pollard [27], i.e., recording individuals sighted within an assumed $5 \times 5 \times 5 \mathrm{~m}$ box in front of the observer walking at a constant pace along a fixed route, and continued along the different habitats. By stopping every $100 \mathrm{~m}$ distance in the transect, butterflies were spotted, identified, tallied, and recorded. When it was not possible to identify on the spot, a representative specimen was trapped and transported to the lab for identification.

Surveys were conducted in sunny conditions, i.e., between $10 \mathrm{AM}$ and $5 \mathrm{PM}$, when butterflies were more active. Counts were made twice per month at 2-week intervals. Different habitats were found in the transect such as forests, grasslands, and field crops/farmlands. During the study period, eight different types of habitats were recognized at each location (forest area). For simplicity, we defined them as follows (see Table 2).

Different references and guidelines established for butterfly monitoring were employed [7]. Field guide to the butterflies of South Africa [28], a complete field guide to butterflies of Australia [29], and a field guide to the butterflies of Africa [30] and on the pierid butterflies of West Shewa zone (Ethiopia) (Lepidoptera: Pieridae) [31] were used for identification of butterfly species and nomenclature. Meteorology data for each location were obtained from the National Meteorology Agency of western Amhara meteorology stations, Amhara Region, Ethiopia.

2.4. Data Analysis. Patterns of butterfly species occurrence and abundance were analyzed to identify habitats and periods of high butterfly activity, diversity, and uniqueness. Differences in butterfly abundance among the different habitats were compared using ANOVA and their means plotted in bar graphs. Relationship between abundance and weather variables was explored using correlation analysis and then regression analysis using SAS version 9.2.

2.5. Diversity Indices. Diversity indices, species accumulation curves, rarefaction curves, and species richness estimates were computed using Biodiversity Analysis Software PAST 4.03 [32]. These statistics apply to association data, where the number of individuals is tabulated with rows (assigned to the name of the taxa) and several columns (assigned to habitats, locations, or sampling dates) to establish associations between taxa in rows and factors in columns. It is based on the number of taxa as well as the number of individuals.

The following 11 diversity indices were used in the present investigation:

(1) Dominance $(D)=1$-Simpson's index, which ranges from 0 (all taxa are equally present) to 1 (one taxon dominates the entire community completely).

(2) Simpson's index $(1-D)=1$-dominance, which measures 'evenness' of the community from 0 to 1 .

(3) Shannon index (entropy) is a diversity index, taking into account the number of individuals as well as the number of taxa. It varies from 0 for communities with only a single taxon to high values (as 


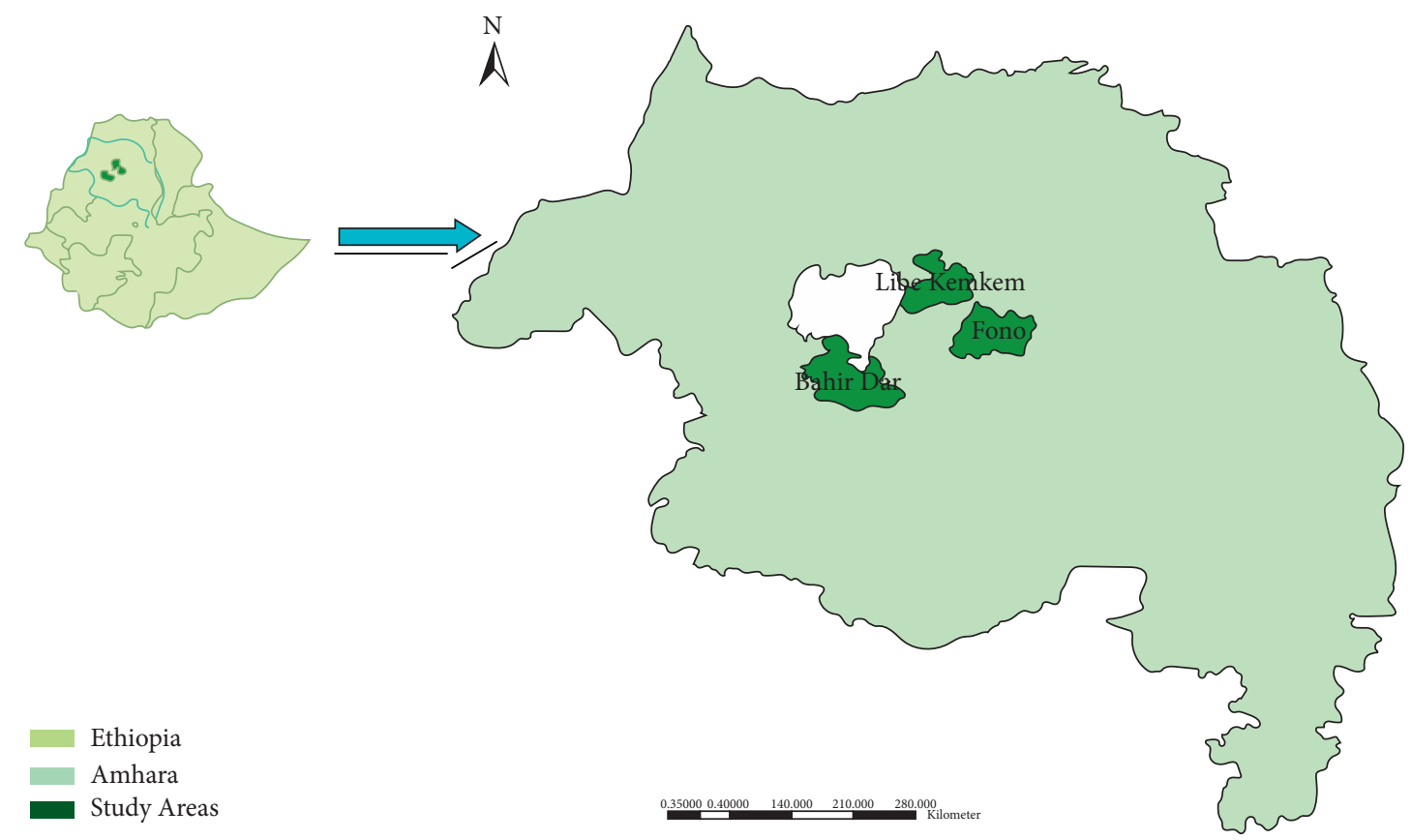

FIgURE 1: Map of the study area (source: Bahir Dar University, Bahir Dar, Ethiopia).

TABLE 1: Environmental variables of study locations.

\begin{tabular}{|c|c|c|c|c|c|c|c|c|}
\hline \multirow[t]{2}{*}{ Study locations } & \multirow[t]{2}{*}{ Latitudes } & \multirow[t]{2}{*}{ Longitudes } & \multirow[t]{2}{*}{ Altitude (m) } & \multicolumn{2}{|c|}{$\begin{array}{c}\text { Temperature } \\
\left({ }^{\circ} \mathrm{C}\right)\end{array}$} & \multirow{2}{*}{$\begin{array}{l}\text { Annual total } \\
\text { rainfall }(\mathrm{mm})\end{array}$} & \multirow[t]{2}{*}{ Area (ha) } & \multirow[t]{2}{*}{ References } \\
\hline & & & & Min & $\operatorname{Max}$ & & & \\
\hline Tara Gedam & $12^{\circ} 07^{\prime \prime} \mathrm{N}$ & $37^{\circ} 47^{\prime \prime} \mathrm{E}$ & $2217-2457$ & 8.7 & 30.5 & 1300 & 875 & [22] \\
\hline Alemsaga & $11^{\circ} 55^{\prime \prime} \mathrm{N}$ & $37^{\circ} 56^{\prime \prime} \mathrm{E}$ & $2180-2470$ & 15.0 & 30.0 & 1300 & 814 & {$[23,24]$} \\
\hline Mount Bezawit* & $11^{\circ} 36^{\prime \prime} \mathrm{N}$ & $37^{\circ} 23^{\prime \prime} \mathrm{E}$ & 1801 & 10.0 & 32.0 & $850-1250$ & 5000 & {$[21,25,26]$} \\
\hline
\end{tabular}

${ }^{*}$ In Mount Bezawit, the Millennium Park is found which was established since the turn of Ethiopia's $21^{\text {st }}$ century and in the present study, Mount Bezawit includes Peda Campus's riverine forest, Bahir Dar University, Bahir Dar, Ethiopia. Bezawit borders east of the Blue Nile River (locally known as Abay River), and Peda Campus is found west of the river. Only a part of the 5000 ha was covered in the study, which was a part adjacent to the campus, not the entire riverine area. Various habitats were studied at each location using transects.

TABLE 2: Definition of habitats.

\begin{tabular}{lc}
\hline Habitat type & Definition \\
\hline $\begin{array}{l}\text { Forest (woody) } \\
\text { Forest edge }\end{array}$ & Forest proper, the actual forest area interior \\
Grassland & The transition zone from woodland or forest to fields or other open spaces \\
Open grassland & Areas where grasses dominate the vegetation, though sedges and other herbs could be found \\
Wetland & Land dominated by grasses and found outside the forest area \\
Open land & Land or soil soaked in water permanently or transiently and on which plants grow \\
Cultivated land & Land where no or very few plants were found, mostly bare flat land \\
Disturbed land & Land cultivated for growing crops
\end{tabular}

high as 5) for communities with many taxa, each with a few individuals. It compares the diversity between various habitats [33].

(4) Menhinick's richness index is the ratio of the number of taxa to the square root of the sample size.

(5) Margalef s richness index is an index used for small samples. It can be measured as $H=(S-1) / \ln N$, where $H$ stands for Margalef's index, $S$ for the number of species, and $N$ for the total number of individuals.
(6) Equitability (also known as Pielou's evenness) is Shannon diversity divided by the logarithm of the number of taxa. This measures the evenness with which individuals are divided among the taxa present. $J=\mathrm{H}^{\prime} / \log (S)$, where $H$ stands for Shannon index and $S$ for the number of observed species in the community.

(7) Fisher's alpha is a diversity index, defined implicitly by the formula $S=\alpha \ln (1+n / \alpha)$, where $S$ is the 
number of taxa, $n$ is the number of individuals, and $\alpha$ is Fisher's alpha. Fisher's $\alpha$ measures diversity within a population and it is considered the best diversity index for many communities of species, including Lepidoptera [34].

(8) Buzas and Gibson's evenness: $E=e^{H^{\prime}} / S$, where $H$ is Shannon index and $S$ is the number of species. $E$ is the measure of evenness or equitability.

(9) Brillouin's index is more sensitive to species abundance and is calculated as $\mathrm{HB}=\ln (N !)-\ln \left(n_{i} !\right)$, where HB stands for Brillouin's index, $N$ for the total number of individuals in the sample, $n_{i}$ is the number of individuals of species $i$, and $\ln (x)$ refers to the natural logarithm of $x$.

(10) Berger-Parker dominance: simply the number of individuals in the most dominant taxon relative to $n$. A simple mathematical expression relates species richness and abundance and takes only the commonest species in the sample. $d=N_{\max } / N$, where $N_{\text {max }}$ stands for the number of individuals in the most abundant species and $N$ is the total number of species. It expresses proportional importance of most abundant species.

(11) Chao 1, bias corrected, is an estimate of total species richness based on the numbers of singleton and doubleton species. Formula: chao $1=S \_$obs $+N \_1\left(N \_1-1\right) /\left(2 *\left(N \_2+1\right)\right)$, where $N \_1$ and $N \_2$ are counts of singletons and doubletons, respectively.

2.6. Rarefaction Curves. Given a column of abundance data for a number of taxa, rarefaction curves give an estimate of how many taxa you would expect to find in a sample with a smaller total number of individuals. With this method, one can compare the number of taxa in samples of different sizes. Using rarefaction analysis on your largest sample, you can read out the number of expected taxa for any smaller sample size, the algorithm of which is from Krebs [35]. Therefore, using the collected data, rarefaction curves were plotted to determine the number of butterfly taxa (species) that could be discovered at different sampling intensities in different habitats.

2.7. Cluster Analysis. Comparisons of species composition between different habitats were estimated using single linkage cluster analysis based on Bray-Curtis similarity [36], which is a model used for abundance data.

2.8. Ordination Analysis Using Detrended Correspondence Analysis. A statistical visualization method known as detrended correspondence analysis (a modified form of correspondence analysis) was used for picturing the association between the levels of two-way contingency tables. In a two-way contingency table (count data), the observed association of two traits is summarized by the cell frequencies, and a typical inferential aspect is whether a certain level of one characteristic is associated with some level of another. The technique displays the rows and columns of a two-way contingency table as points in a low-dimensional space. In the current case, detrended correspondence analysis was invoked with butterfly species in rows and their habitats, study locations, or sampling dates in columns using PAST 4.03 software [32].

\section{Results}

3.1. Butterfly Fauna. During this study, a total of 27,568 individuals of 11 butterfly species belonging to three families, five subfamilies, and eight genera were found at three sites from mid-October to mid-June. The numbers of individuals recorded in each vegetation type were 23,610 in the forest area, 2094 in open land, 684 in the open grassland, 629 in the grassland, 390 in the wetland, 161 in the cultivated land, and 0 in the disturbed land. Eleven species were recorded from the Tara Gedam forest alone followed by nine in Alemsaga forest and seven at Mount Bezawit (see Table 3; Figure 2).

According to the results of the analysis of variance, butterfly abundance significantly varied between species at Mount Bezawit $(F=34.7, P<0.0001)$, at Alemsaga $(F=24.1$, $P<0.0001)$, and at Tara Gedam $(F=25.8, P<0.0001)$ but not between dates of sampling (at Mount Bezawit: $F=1.0$, $P=0.41$; Alemsaga: $F=0.9, P=0.56$, and at Tara Gedam: $F=1.2, P=0.32$ ) (see Table 4 ).

3.2. Total Abundance and Diversity at the Three Locations. Tara Gedam hosted all 11 butterfly species, Alemsaga nine, and Bezawit seven of them (see Figure 3), whereby Belenois spp. and Mylothris agathina were the most abundant in all three study locations. The species Vanessa cardui was found in both Mount Bezawit and Tara Gedam forests but not in the Alemsaga forest. The Charaxes species and the species Papilio nireus lyaeus were found in Alemsaga and Tara Gedam forests but not in Mount Bezawit. Papilio dardanus was unique only to Tara Gedam forest.

\subsection{Butterfly Abundance and Diversity in Different Habitats.} Based on the number of butterflies recorded, abundance and diversity were higher in the forest areas than in other habitats (see Figure 4).

3.4. Butterfly Abundance and Diversity in Different Habitats. Generally, more species were found in forest areas than in other habitats (see Figure 5). Belenois spp. and Mylothris agathina were the most abundant, regardless of location. Junonia terea elgiva, Eronia leda, Phalanta eurytis, Charaxes candiope, Charaxes marieps, Papilio nireus lyaeus, and Papilio dardanus were also found in the forest areas. Grasslands, wetlands, and cultivated and disturbed lands had low butterfly density and diversity. Only one species, i.e., Belenois raffrayi, was found in the grassland habitat and only Mylothris agathina in the open grassland and Vanessa cardui in the wet land. Vanessa cardui, Belenois aurota, Eronia leda, 
TABLE 3: List of butterfly species recorded in the study area.

\begin{tabular}{|c|c|c|c|c|}
\hline Common name & Species name & Genus & Subfamily & Family \\
\hline Forest leopard & Phalanta eurytis & Lachnoptera & Heliconiinae & Nymphalidae \\
\hline Brown veined white & Belenois aurota & Belenois & Pierinae & Pieridae \\
\hline Autumn leaf vagrant & Eronia leda & Eronia & Pierinae & Pieridae \\
\hline Soldier pansy & Junonia terea elgiva & Junonia & Nymphalinae & Nymphalidae \\
\hline Raffray's white & Belenois raffrayi & Belenois & Pierinae & Pieridae \\
\hline Common dotted border & Mylothris agathina & Mylothris & Pierinae & Pieridae \\
\hline Green veined emperor & Charaxes candiope & Charaxes & Charaxinae & Nymphalidae \\
\hline Marieps emperor & Charaxes marieps & Charaxes & Charaxinae & Nymphalidae \\
\hline Green banded swallowtail & Papilio nireus lyaeus & Papilio & Papilioninae & Papilionidae \\
\hline Mocker swallowtail & Papilio dardanus & Papilio & Papilioninae & Papilionidae \\
\hline Painted lady & Vanessa cardui & Vanessa & Nymphalinae & Nymphalidae \\
\hline
\end{tabular}

Junonia terea elgiva, Charaxes candiope, and Papilio nireus lyaeus were found in the open land while only Belenois aurota was found in cultivated land in Mount Bezawit forest. No butterfly species was recorded in the cultivated land in the Alemsaga and Tara Gedam forests and no butterfly species were recorded in disturbed lands.

3.5. Seasonal Population Dynamics. Butterfly numbers were more in October, November, April, May, and June but less from December to March.

3.6. Uniqueness. Tara Gedam contributed one unique species, i.e., Papilio dardanus. Species common to all study areas include Belenois aurota, Belenois raffrayi, Mylothris agathina, Eronia leda, Junonia terea elgiva, and Phalanta eurytis. Three species were common to Alemsaga and Tara Gedam forests (Charaxes candiope, Charaxes marieps, and Papilio nireus lyaeus). One species, i.e., Vanessa cardui, was common to Mount Bezawit and Tara Gedam forests.

3.7. Diversity Indices. At all the three locations, the forest edge was the richest habitat in terms of number of butterfly species (a maximum of 8 species) but not in number of individuals, which in this case was overtaken by the woody forest habitat (see Table 5.). In general, the forest edge and woody forest habitats were the richest in terms of both number of species and number of individuals.

Equitability (Pielou's index) showed equal distribution of the species wherever they were, i.e., 0.8 to 0.9 , except at the open grassland at Tara Gedam (0.3). It looks that at the open grassland of Tara Gedam, there was a sign of dominance of a species, which was supported by a dominance $D$ value of 0.92 . Shannon's index was also higher at the woody forest habitat than others at two of the three locations (at Alemsaga and Tara Gedam); the maximum (1.8) was observed at Tara Gedam.

Margalef index varied between habitats and locations showing differences in species richness (from 0.25 at the woody forest of Mount Bezawit to 0.86 at the forest edge of Tara Gedam). Fisher's alpha had the highest diversity at the forest edge, the woody forest, and the open land, in order of magnitude. This agrees with Shannon's diversity stated above. Irrespective of location, evenness was higher at the woody forest and the open land habitats than at the other habitats, which varied between 0.6 and 0.9. The highest Berger-Parker index was found at the open grassland habitat of Tara Gedam (0.96).

\subsection{Detrended Correspondence Analysis}

3.8.1. Association between Study Locations and Their Habitats. According to the detrended correspondence analysis conducted to determine the association between study locations and habitats, the first axis explained about $92 \%$ and the second axis about $5 \%$ of the relationship (Pearson's $\chi^{2}$ ) between the two factors, i.e., locations and habitats (see Figure 6(a)). For column points, i.e., habitats, only one habitat (wetland) is sufficiently far from the centroid of both axes, thus contributing to the association. In the case of locations (rows), particularly Mount Bezawit and to some extent Alemsaga were far from the centroid and lie along the horizontal dimension (axis 1). Axis 1 seems to be determined largely by the number of butterflies counted in Mount Bezawit and Alemsaga locations. In general, the plot shows that more butterflies at Mount Bezawit than one would expect, if the rows and columns were independent, belong to the cultivated land, and more butterflies in other locations than expected, if the rows and columns were independent, belong to other habitats.

\subsubsection{Association between Habitat and Butterfly Species.} Axis 1 (dimension 1) explained $81 \%$ of the association between species and habitats and axis 2 just 13.7\% (see Figure 6(b)). The wetland and to some extent forest edge and open land habitats were found away from the centroid of axis 1 , contributing to the observed association. Other habitats were concentrated near to the centroid and therefore could not contribute to the association.

Butterfly species $V$. cardui and J. terea and to some extent B. aurota and E. leda were found away from the centroid contributing to much of the association between species and habitats. This also implies that, compared to other species, $V$. cardui, J. terea, B. aurota, and E. leda were particularly associated with the wetland and forest edge habitats. That does not, however, mean that they were not found in other 


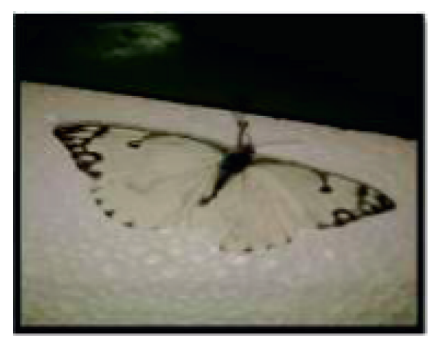

Belenois aurota (Fabricius,1973)

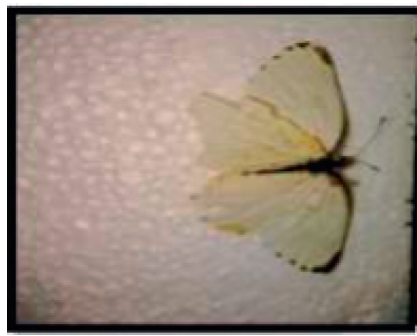

Mylothris agathina (Cramer,1779)

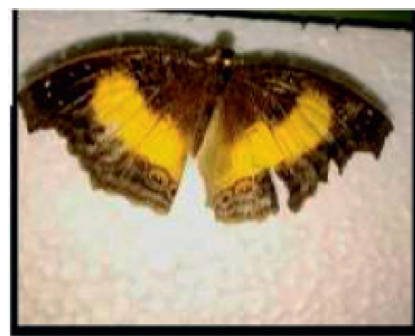

Junonia terea elgiva (Druce, 1773)

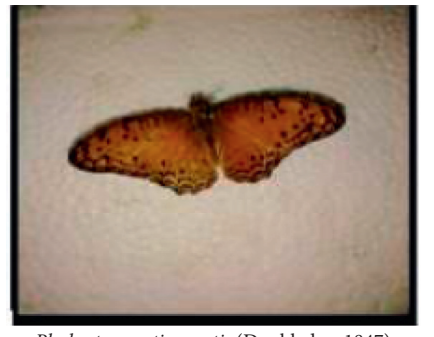

Phalanta eurytis eurytis (Doubleday, 1847)

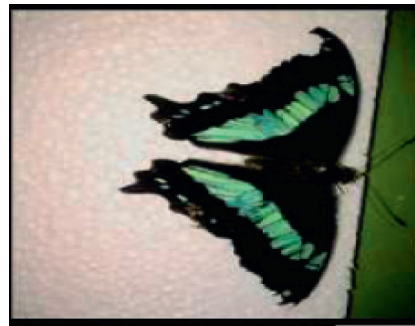

Papilio nireus lyaeus (Linnaeus, 1758)

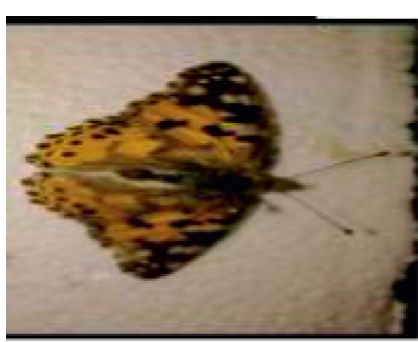

Vanessa cardui (Linnaeus, 1758)

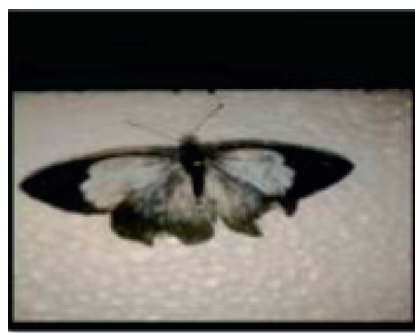

Belenois raffrayi (Oberthür,1878)

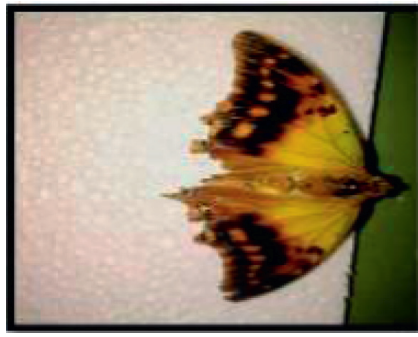

Charaxes candiope (Godrat,1824)

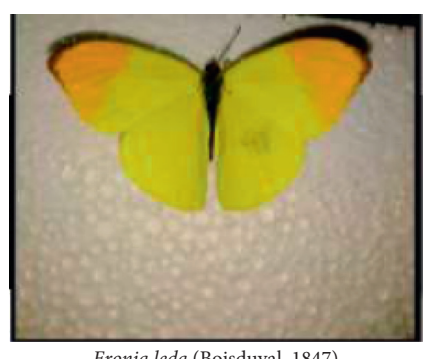

Eronia leda (Boisduval, 1847)

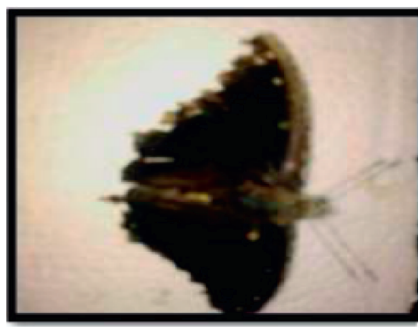

Charaxes marieps (Vansomeren and Jackson, 1957)

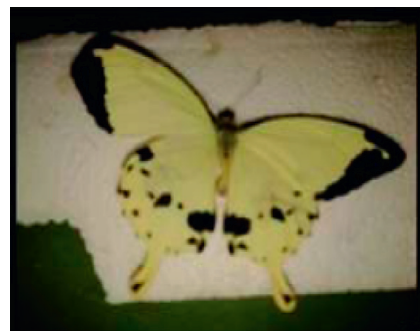

Papilio dardanus (Brown, 1976)

Figure 2: Butterfly species recorded at different locations (photo by the second author). 
TABLE 4: Two-way analysis of variance tables for abundance of butterfly species at different locations.

\begin{tabular}{|c|c|c|c|c|c|c|}
\hline Location & Source of variation & SS & $d f$ & MS & $F$ & $P$ value \\
\hline \multirow{4}{*}{ Mount Bezawit } & Sample date & 6704.6 & 6 & 419.0 & 1.1 & 0.4142 \\
\hline & Species & 83319.4 & 6 & 13886.6 & 34.8 & $4.99 \mathrm{E}-22$ \\
\hline & Error & 38347.4 & 96 & 399.5 & & \\
\hline & Total & 128371.5 & 18 & & & \\
\hline \multirow{4}{*}{ Alemsaga } & Sample date & 7212.9 & 16 & 450.8 & 0.9 & 0.5650 \\
\hline & Species & 95915.5 & 8 & 11989.4 & 24.1 & $3.26 \mathrm{E}-22$ \\
\hline & Error & 63757.4 & 128 & 498.1 & & \\
\hline & Total & 166885.8 & 152 & & & \\
\hline \multirow{4}{*}{ Tara Gedam } & Sample date & 8214.3 & 6 & 513.4 & 1.2 & 0.3174 \\
\hline & Species & 115893.2 & 10 & 11589.3 & 25.9 & $1.08 \mathrm{E}-28$ \\
\hline & Error & 71649.4 & 70 & 447.8 & & \\
\hline & Total & 195756.6 & 86 & & & \\
\hline
\end{tabular}

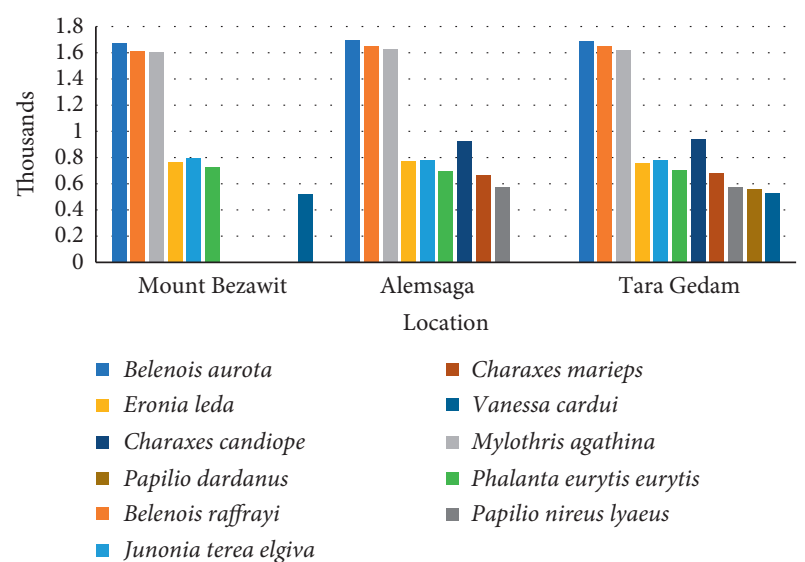

Figure 3: Abundance of butterfly species in the three study sites (Mount Bezawit, Alemsaga, and Tara Gedam forests).

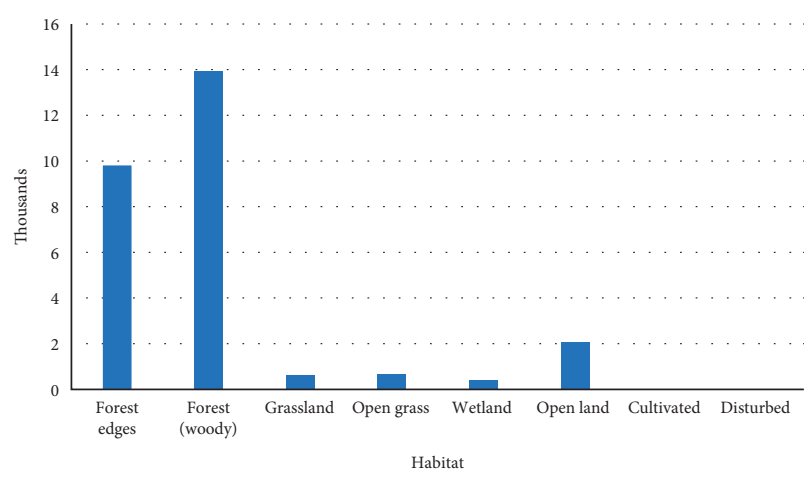

FIGURE 4: Total number of butterflies counted at different habitats.

habitats. It only means that the numbers of individuals of these species were more here than other species were.

The other species were found close to the centroid on axis 1 , which implies that they could not contribute much to the association.

3.8.3. Association between Butterfly Species and Date of Sampling (Seasonal Association). In Mount Bezawit, axis 1 explained $89.5 \%$ of the association and axis 2 only $10.2 \%$ (see Figure 7(a)). Months that ran from late December to March were found at the extreme right of the plot, while October and 21 June were at the left of the plot, explaining much of the association between species and sampling dates. Other sampling dates were either close to the centroid or not very far from it and therefore could not account for any considerable association between species and sampling dates. Compared to other butterfly species recorded in this study, E. leda was found at the right of the plot, suggesting its contribution to the association and its particular association to the dates of sampling from late December to March.

In Alemsaga, the first axis explained $80 \%$ of the association between species and sampling dates and the second axis $16.4 \%$ (see Figure 7(b)). The months starting from the end of December to March were found at the right side of the plot on axis 1 as opposed to May, which was found at the left side of the plot, explaining much of the association between species and sampling dates. P. nireus lyaeus and E. leda were found at the right and happen to be associated with the months of January, February, March, and May (notice April was not a part). Early December, November, and April were close to the centroid and did not contribute to the association.

In Tara Gedam, axis 1 explained $90.6 \%$ of the association and axis 2 about $8.7 \%$ (see Figure 7(c)). It appears that January, February, and March at the extreme right and May at the left explained the association, or differences thereof, between species and date of sampling. P. nireus lyaeus and E. leda were found farther at the right, away from the origin (centroid), better explaining the association between the species and date of sampling. Other species were either close or right to the centroid, thus contributing little to the association. In terms of abundance, $P$. nireus lyaeus was more associated with the months of January, February, and March than it was in other months.

3.9. Rarefaction Curve. Rarefaction curves rose quickly at the forest edge and woody forest habitats than other forests and then leveled off thereafter (see Figure 8). The open grassland habitat had the lowest rising curve.

3.10. Species Composition (Cluster Analysis). The cluster analysis based on the Bray-Curtis single linkage similarity index showed differences and similarities between the butterfly species composition recorded in the eight habitat 


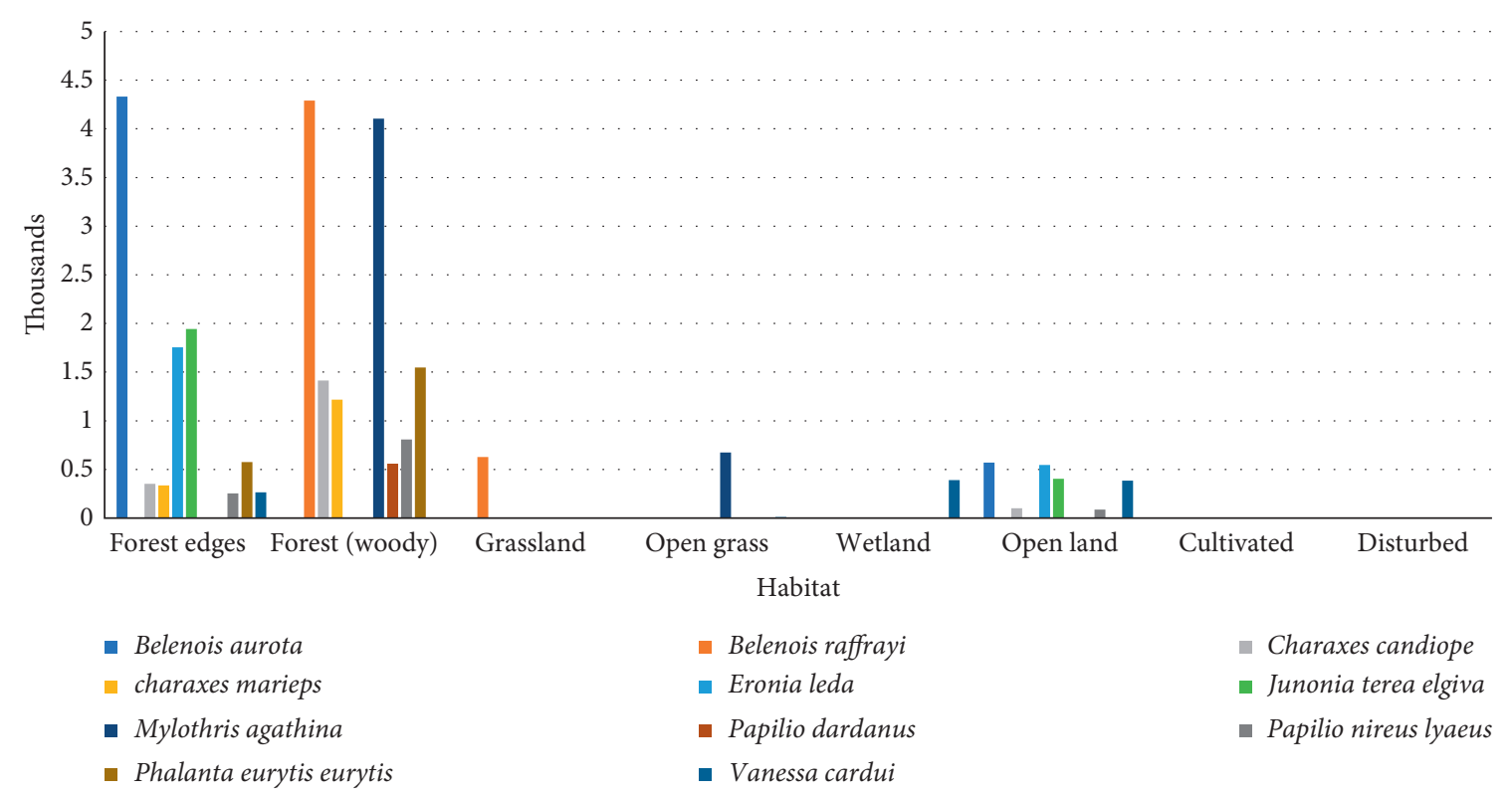

FIGURE 5: Abundance of butterfly species in different habitats of northwest Ethiopia, particularly in the three study areas.

types. The disturbed and cultivated habitats stood out clearly separated from the rest of the habitats and showed linkage at almost $0 \%$ similarity, which represented the lowest similarity. The grassland habitat was linked at about $10 \%$ similarity to the cluster of habitats of wetland, open land, and forests. The woody forest was linked at about $15 \%$ similarity to the cluster of wetland, open land and forest edge habitats. The wetland was linked at about $34 \%$ to the open land, and forest edge habitats (see Figure 9). The highest similarity recorded was $100 \%$ between disturbed and cultivated habitats.

\subsection{Correlation Analysis of Butterfly Abundance with} Weather Variables. Butterfly population was found positively correlated with rainfall at the three locations (see Table 6). It also had a high positive correlation with minimum temperature at Alemsaga and Tara Gedam but not at Mount Bezawit. Its correlation with maximum temperature was not consistent at the three locations because it showed high positive at Mount Bezawit and weak negative correlation at Alemsaga and Tara Gedam. According to the regression analysis, the abundance of butterflies was positively related with the amount of rainfall at two of the three locations and with the minimum temperature (see Table 7). In contrast, maximum temperature was negatively related to abundance.

\section{Discussion}

Despite the fact that some effort has been made to assess butterfly diversity in western Ethiopia [31], the current study was the first of its kind in Tana Basin area (northwestern Ethiopia). The presence of different species of butterflies was confirmed for the first time in northwestern Ethiopia, particularly in Mount Bezawit, Alemsaga, and Tara Gedam forests and their surroundings. Butterflies could be used as indicators of habitat diversity and health but also to document changes in butterfly communities in time and space [37].
Many agents and factors have now threatened the once rich natural habitats of butterflies in the study area. This is a situation that needs immediate action, i.e., an action that preserves those habitats before it is too late, and before many more butterfly taxa get extinct. The ultimate goal of the current study was therefore estimating the biodiversity of butterflies in the study area and laying the foundation for habitat preservation and butterfly conservation. An inventory of butterfly taxa was conducted at different habitats at three locations.

In this study, therefore, a total of 27,568 individuals of different butterfly species were recorded that belonged to 11 species, eight genera, three families, and five subfamilies at three sites from mid-October to mid-June in two-week intervals. The number of individuals recorded in each vegetation type included 23,610 in the forest area, 2094 in open land, 684 in open grassland, 629 in grasslands, 390 in wetland, 161 in cultivated land, and none in the disturbed land. Eleven species were recorded from Tara Gedam forest area followed by nine from Alemsaga forest and seven from Mount Bezawit forest.

In this study, more individuals/specimens and a smaller number of genera and species were found compared to certain other reports, indicating lower diversity. One reason for this condition was that the same area was sampled over and over again across different seasons (time factor), 17 field trips in total, thereby inflating numbers. Secondly, many habitats each at three geographically distinct locations were assessed, again significantly increasing numbers. Those conditions had the potential to double or triple the numbers compared to other studies. More of the same taxa were practically seen at any one site and time. This is what a careful observer can notice any time anywhere in that area.

Other workers have reported more taxa and less population than the present study $[38,39]$. Habitat differences are the plausible reasons. Menagesha forest and Jimma area 
TABLE 5: Diversity indices for butterfly communities at different habitat types.

\begin{tabular}{|c|c|c|c|c|c|c|c|}
\hline & Forest edges & Woody forest & Grass land & Open grassland & Wet land & Open land & Cultivated land \\
\hline \multicolumn{8}{|l|}{ Mount Bezawit } \\
\hline Taxa $(S)$ & 5 & 3 & 1 & 1 & 1 & 4 & 1 \\
\hline Individuals & 3072 & 3455 & 148 & 160 & 287 & 411 & 161 \\
\hline Dominance $(D)$ & 0.315 & 0.379 & 1 & 1 & 1 & 0.267 & 1 \\
\hline Simpson $(1-D)$ & 0.685 & 0.621 & 0 & 0 & 0 & 0.733 & 0 \\
\hline Shannon $\left(H^{\prime}\right)$ & 1.328 & 1.02 & 0 & 0 & 0 & 1.353 & 0 \\
\hline Evenness $(\hat{e} H / S)$ & 0.754 & 0.925 & 1 & 1 & 1 & 0.968 & 1 \\
\hline Brillouin & 1.323 & 1.018 & 0 & 0 & 0 & 1.332 & 0 \\
\hline Menhinick & 0.090 & 0.051 & 0.082 & 0.079 & 0.0591 & 0.197 & 0.079 \\
\hline Margalef & 0.498 & 0.246 & 0 & 0 & 0 & 0.499 & 0 \\
\hline Equitability $(J)$ & 0.825 & 0.929 & & & & 0.976 & \\
\hline Fisher alpha & 0.584 & 0.323 & 0.144 & 0.142 & 0.130 & 0.615 & 0.142 \\
\hline Berger-Parker & 0.467 & 0.425 & 1 & 1 & 1 & 0.343 & 1 \\
\hline Chao 1 & 5 & 3 & 1 & 1 & 1 & 4 & 1 \\
\hline \multicolumn{8}{|l|}{ Alemsaga } \\
\hline Taxa $(S)$ & 7 & 6 & 1 & 1 & & 5 & \\
\hline Individuals & 3172 & 4837 & 276 & 291 & & 824 & \\
\hline Dominance $(D)$ & 0.270 & 0.207 & 1 & 1 & & 0.275 & \\
\hline Simpson $(1-D)$ & 0.730 & 0.793 & 0 & 0 & & 0.725 & \\
\hline Shannon $\left(H^{\prime}\right)$ & 1.577 & 1.675 & 0 & 0 & & 1.397 & \\
\hline Evenness $(\hat{e} H / S)$ & 0.691 & 0.8890 & 1 & 1 & & 0.809 & \\
\hline Brillouin & 1.57 & 1.671 & 0 & 0 & & 1.382 & \\
\hline Menhinick & 0.124 & 0.086 & 0.060 & 0.0589 & & 0.174 & \\
\hline Margalef & 0.744 & 0.589 & 0 & 0 & & 0.596 & \\
\hline Equitability $(J)$ & 0.810 & 0.935 & & & & 0.868 & \\
\hline Fisher alpha & 0.851 & 0.676 & 0.1306 & 0.130 & & 0.708 & \\
\hline Berger-Parker & 0.444 & 0.285 & 1 & 1 & & 0.353 & \\
\hline Chao 1 & 7 & 6 & 1 & 1 & & 5 & \\
\hline \multicolumn{8}{|l|}{ Tara Gedam } \\
\hline Taxa $(S)$ & 8 & 7 & 1 & 2 & 1 & 6 & \\
\hline Individuals & 3498 & 5576 & 205 & 233 & 103 & 859 & \\
\hline Dominance $(D)$ & 0.257 & 0.180 & 1 & 0.918 & 1 & 0.235 & \\
\hline Simpson $(1-D)$ & 0.743 & 0.820 & 0 & 0.082 & 0 & 0.765 & \\
\hline Shannon $\left(H^{\prime}\right)$ & 1.643 & 1.826 & 0 & 0.177 & 0 & 1.585 & \\
\hline Evenness $(\hat{e} H / S)$ & 0.646 & 0.887 & 1 & 0.597 & 1 & 0.814 & \\
\hline Brillouin & 1.636 & 1.822 & 0 & 0.168 & 0 & 1.568 & \\
\hline Menhinick & 0.135 & 0.094 & 0.070 & 0.131 & 0.0985 & 0.205 & \\
\hline Margalef & 0.858 & 0.696 & 0 & 0.184 & 0 & 0.740 & \\
\hline Equitability $(J)$ & 0.79 & 0.938 & & 0.2555 & & 0.885 & \\
\hline Fisher alpha & 0.978 & 0.790 & 0.137 & 0.301 & 0.154 & 0.870 & \\
\hline Berger-Parker & 0.425 & 0.259 & 1 & 0.957 & 1 & 0.355 & \\
\hline Chao 1 & 8 & 7 & 1 & 2 & 1 & 6 & \\
\hline
\end{tabular}

are the most stable and undisturbed habitats in the whole of Ethiopia even up to this day. More diversity is expected in these areas of Ethiopia, where pastoralism and growing vegetables and root crops were the tradition for centuries. These practices of the population helped maintain the natural setting, enhancing diversity. These areas are still tropical rainforests (the birth place of coffee under the huge tree canopies), reminiscent of what was Ethiopia like centuries ago.

The current study area, on the other hand, was cultivated for thousands of years, and the forest was cleared and replaced by annual crops that originated in the Middle East (the Fertile Crescent), Africa, and Ethiopia. In these conditions, big diversity is not expected.

In terms of habitat, during this study, regardless of location, forest areas hosted more butterfly diversity and populations. This is because butterflies are primarily a tropical group of insects and often depend on rain forest plants for larval food [29]. Similarly, according to studies from Manembo-Nembo Wildlife Reserve (Indonesia), more abundant and diversified butterflies were found in riverside habitats in the forest, which is a source of food and shelter [40]. In contrast, in Sicily, Italy, grasslands were found to be the most suitable for butterflies because grasslands provide the food and shelter the larvae need [41]. Yet, it is also believed that forests support many butterfly taxa because of the range of food and habitat they provide. Surrounding forests are beneficial for many grassland butterfly species and those forests might mitigate the negative effects of habitat loss caused by agricultural intensification [42]. The so-called grasslands in the current study in Ethiopia were low density and short grasses and herbs, which practically could not support high butterfly density. Forested areas 


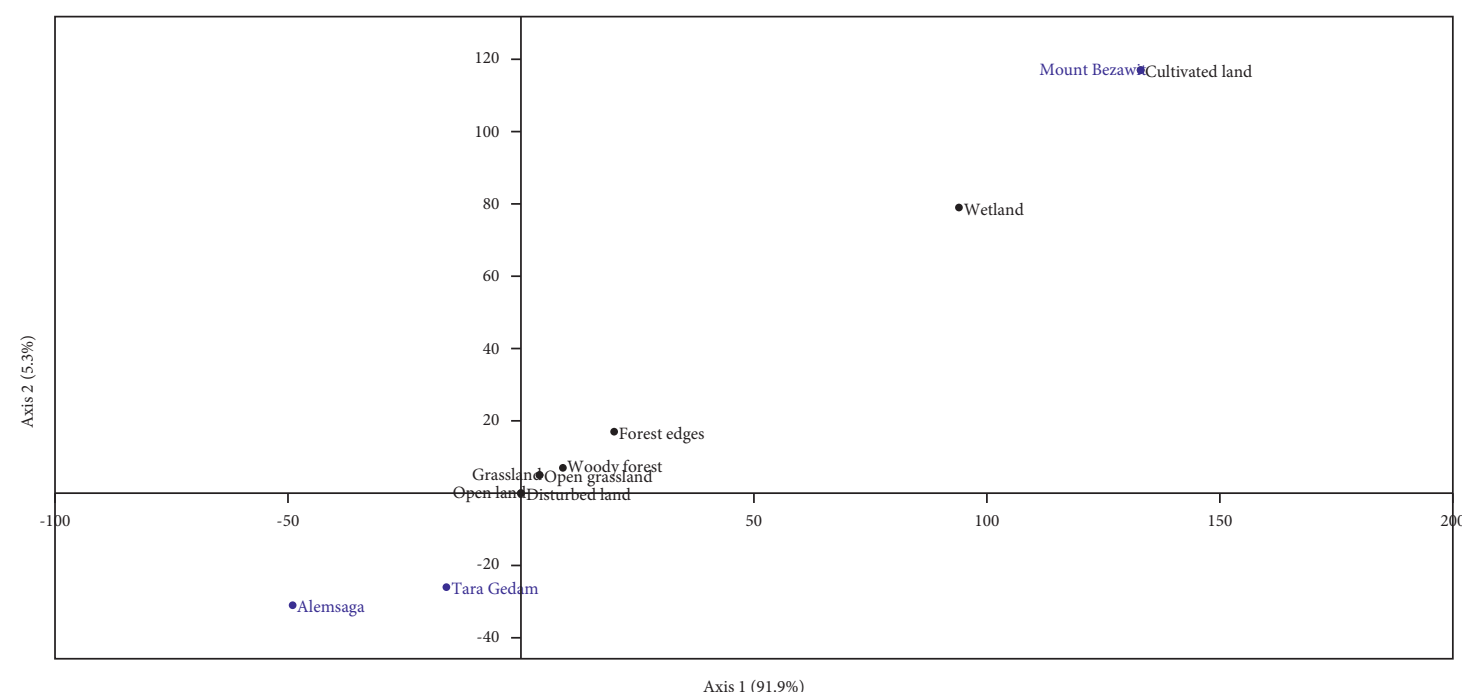

(a)

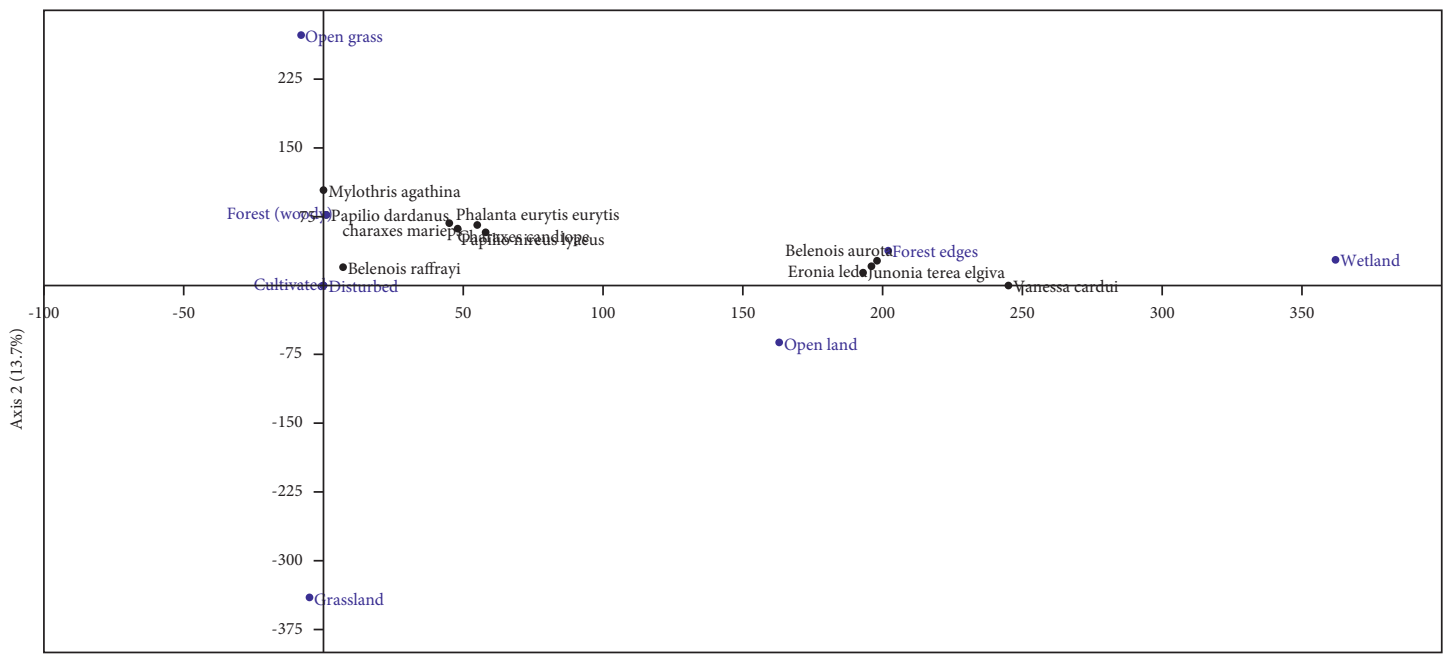

Axis $1(80.8$

(b)

FIgURe 6: Ordination of study location and habitats (a) and habitats and butterfly species (b) by detrended correspondence analysis in Tana Basin (northwestern Ethiopia).

supported butterflies more effectively because of the sheer size and variety of biomass they provided.

Williams [30] underscores that forest areas are rich in butterfly diversity. While arthropods serve as good indicators of habitat biodiversity because they respond quickly to environmental changes, butterflies and moths in general constitute the second largest order of arthropods that widely occur in humid tropical forests [43]. Animal and insect species diversity correlates strongly with the structural complexity of habitats and the diversity of vegetation. Food quality also may influence the occurrence of herbivores. Similarly, high butterfly diversity was reported in Menagesha State Forest, Ethiopia [20]. The present study showed that butterflies were not found in disturbed lands; this supports the idea that degraded habitats affect the population of butterflies. Generally, the diversity of butterflies depends on habitat management and butterfly species richness increases with increasing diversity of plants and decreases with increasing degradation of vegetation. Among the 11 species identified, Belenois spp. and Mylothris agathina were also recorded in a previous study conducted in West Shewa zone of Ethiopia [31].

Seasonal population dynamics was observed as butterfly numbers were more in October, November, April, May, and June, but less from December to March. Knowledge of butterfly flight season in abundance can serve the purpose of monitoring and conservation programs, when there are any [41]. The decline in butterfly abundance from December to March corresponded to the dry season.

According to the results of the current study, the indices of Shannon's index and Margalef richness were consistently higher in forests and open land habitats. While high diversity in forests is logical, it is questionable in the open land. In either case, it must be a function of plant biomass. 


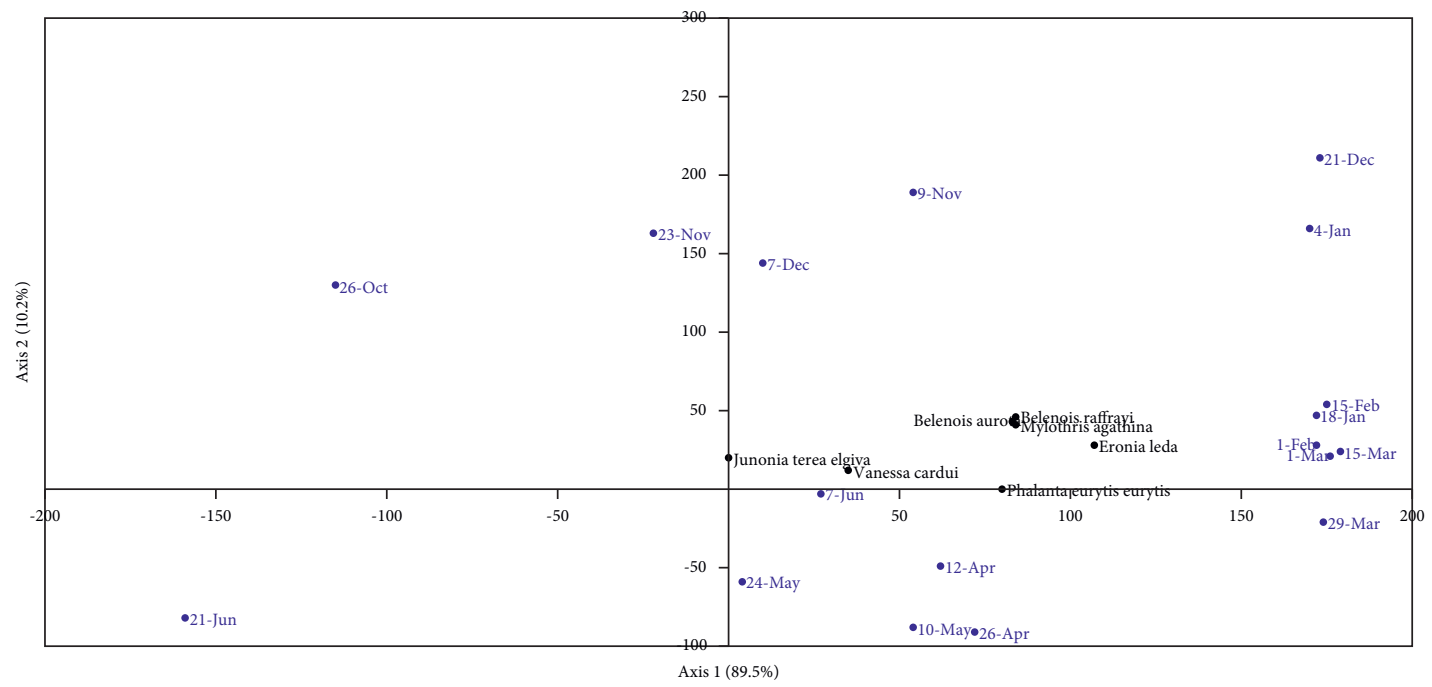

(a)

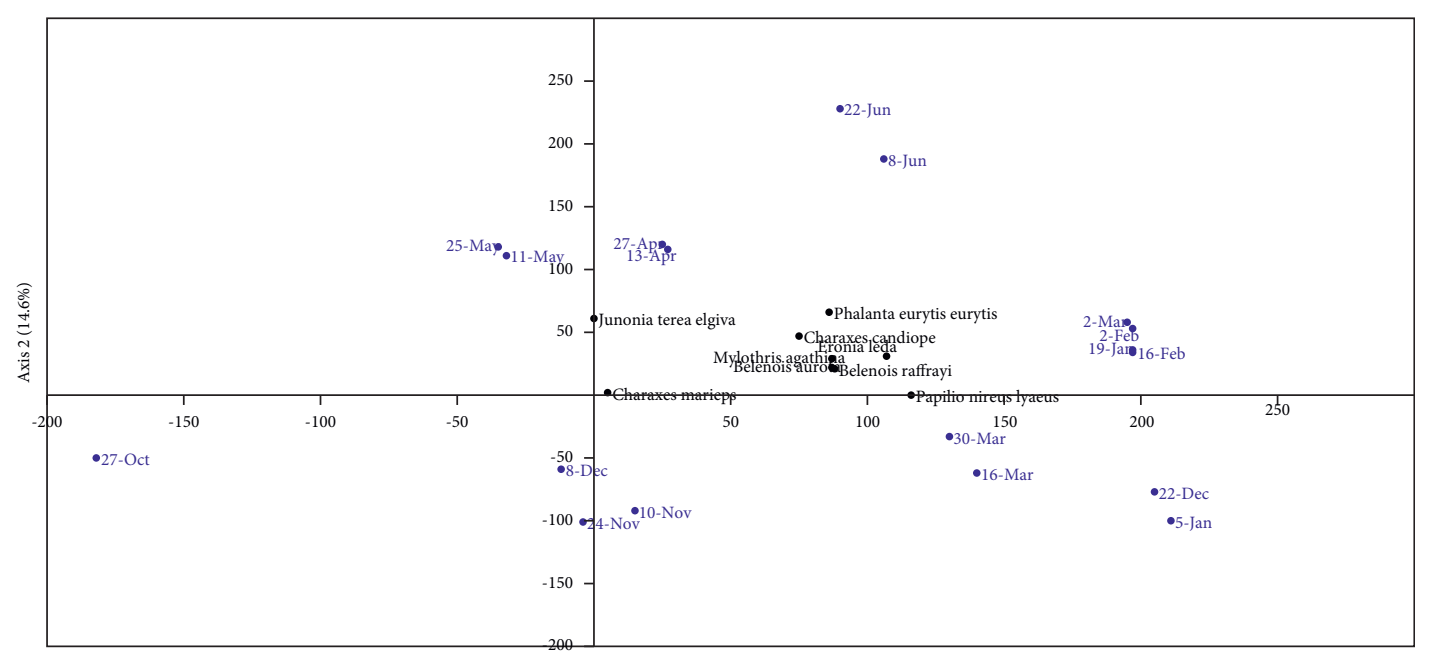

Axis $1(79.9 \%)$

(b)

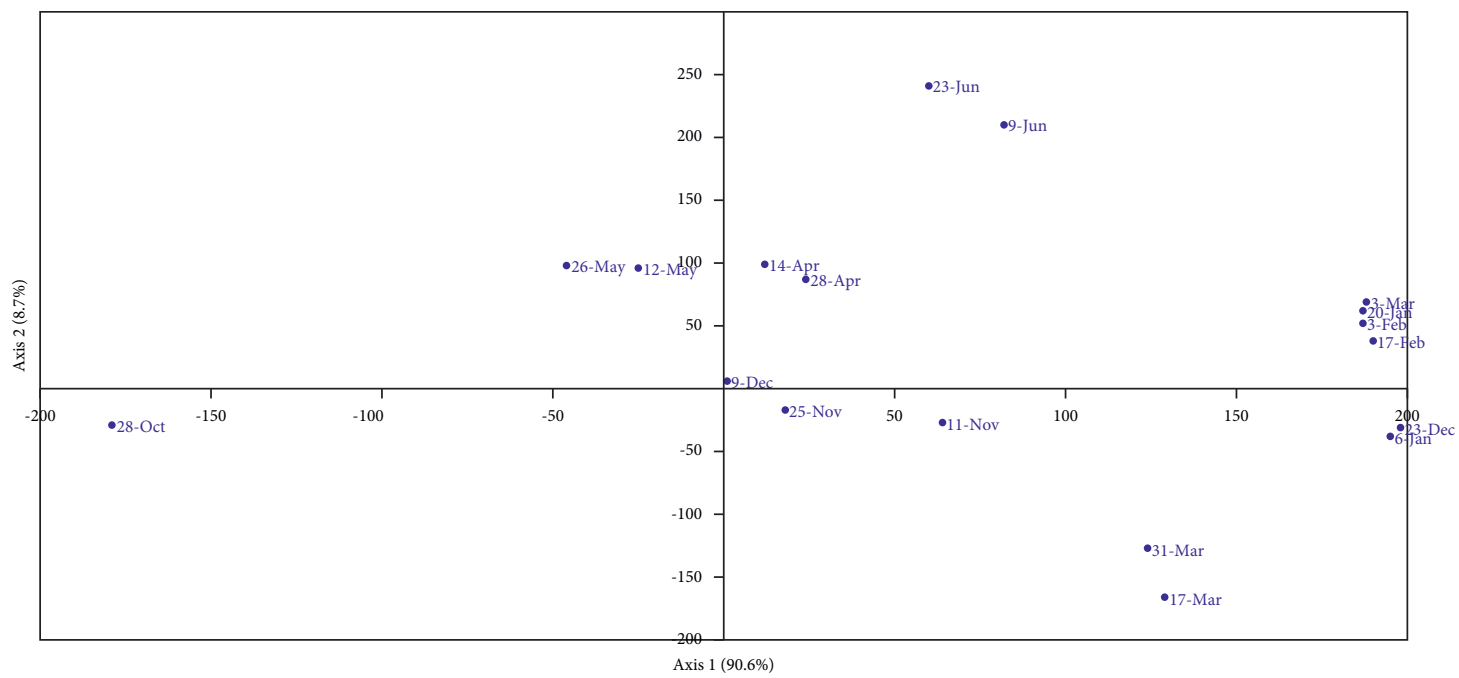

(c)

Figure 7: Ordination of butterfly species and sampling date by detrended correspondence analysis at three locations in Tana Basin (northwestern Ethiopia). (a) Mount Bezawit. (b) Alemsaga. (c) Tara Gedam. 


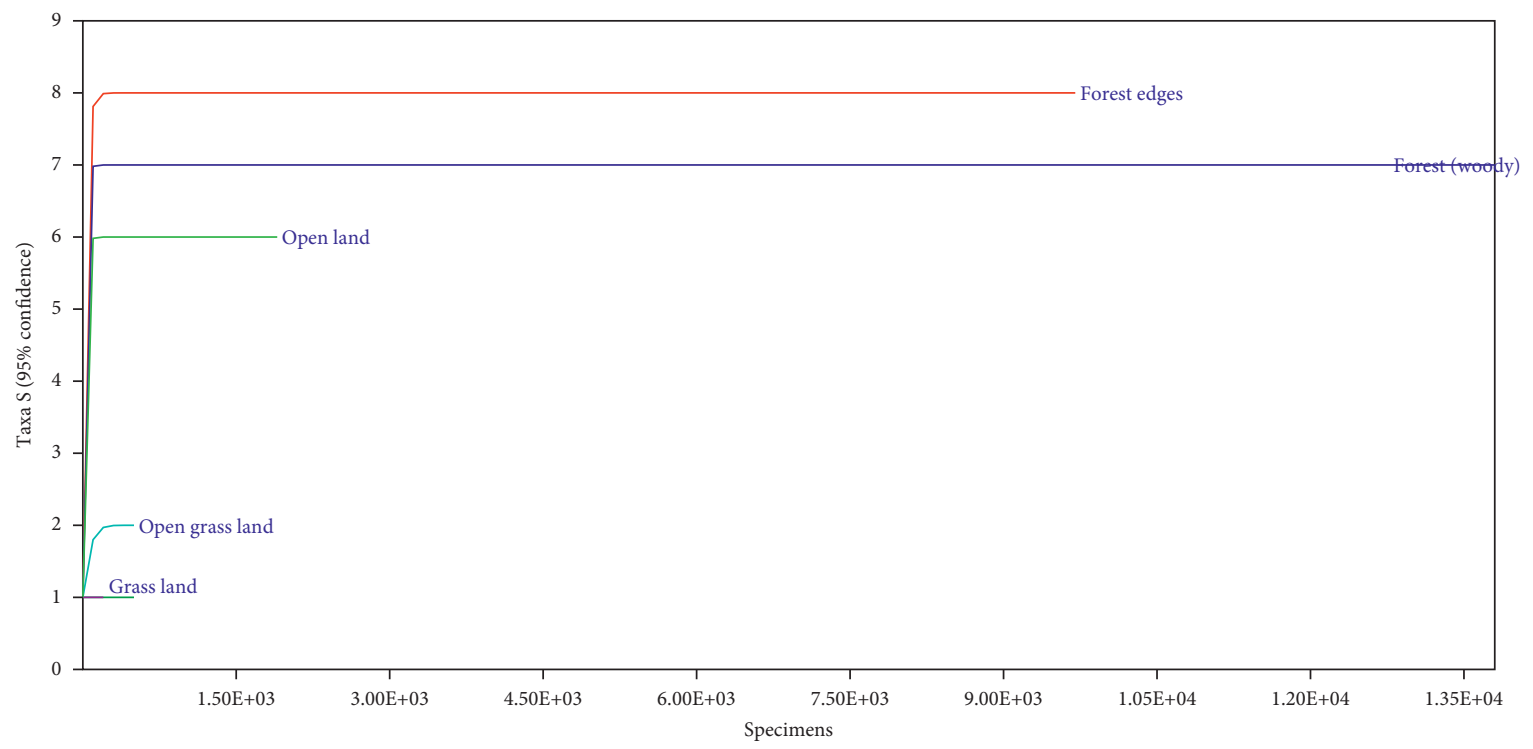

FIGURE 8: Sample based rarefaction curves of estimated butterfly species richness at five different habitats in the Upper Blue Nile basin, Amhara Region, Ethiopia.

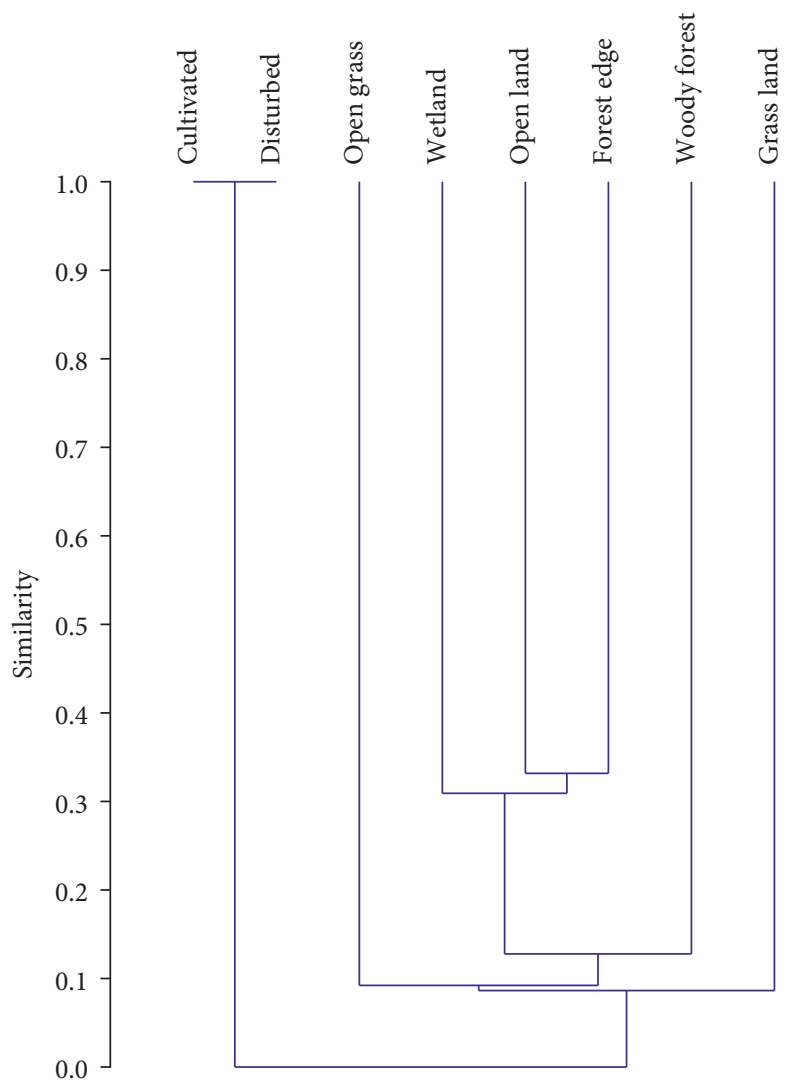

FIGURE 9: Single linkage cluster analysis between habitat types based on Bray-Curtis similarity (short forms denote the following: cultivated stands for cultivated land, disturbed for disturbed land, and open grass for open grassland habitats). 
TABLE 6: Correlation analysis between butterfly abundance and weather variables at three locations.

\begin{tabular}{|c|c|c|c|c|c|}
\hline Location & & NB & $\mathrm{RF}$ & $\operatorname{Min} \mathrm{T}$ & $\operatorname{Max} T$ \\
\hline \multirow{4}{*}{ Mount Bezawit } & Number of butterflies (NB) & 1 & & & \\
\hline & Rainfall (RF) & $0.27^{*}$ & 1 & & \\
\hline & Minimum temperature $(\min \mathrm{T})$ & -0.05 & $0.60^{* *}$ & 1 & \\
\hline & Maximum temperature $(\max \mathrm{T})$ & $0.60^{*}$ & 0.22 & -0.21 & 1 \\
\hline \multirow{4}{*}{ Alemsaga } & Number of butterflies (NB) & 1 & & & \\
\hline & Rainfall (RF) & 0.09 & 1 & & \\
\hline & Minimum temperature $(\min \mathrm{T})$ & $0.61^{*}$ & 0.31 & 1 & \\
\hline & Maximum temperature $(\max \mathrm{T})$ & $-0.29^{*}$ & -0.12 & $-0.41^{*}$ & 1 \\
\hline \multirow{4}{*}{ Tara Gedam } & Number of butterflies (NB) & 1 & & & \\
\hline & Rainfall (RF) & $0.42^{*}$ & 1 & & \\
\hline & Minimum temperature $(\min \mathrm{T})$ & $0.69^{* *}$ & 0.21 & 1 & \\
\hline & Maximum temperature $(\max \mathrm{T})$ & -0.23 & $-0.28^{*}$ & $-0.41^{*}$ & 1 \\
\hline
\end{tabular}

*Significant at $\alpha=0.05$ and ${ }^{* *}$ significance at $\alpha=0.01$.

TABLE 7: Multiple regression analysis between butterfly abundance and weather variables.

\begin{tabular}{|c|c|c|c|c|c|}
\hline Location & & Coefficients & Standard error & $t$ value & $P$ value \\
\hline \multirow{4}{*}{ Mount Bezawit } & Intercept & 436.06 & 37.31 & 11.69 & $1.31 \mathrm{E}-08$ \\
\hline & $\mathrm{RF}$ & 11.74 & 9.41 & 1.25 & 0.2327 \\
\hline & Min $\mathrm{T}$ & -3.86 & 2.67 & -1.44 & 0.1708 \\
\hline & $\operatorname{Max} \mathrm{T}$ & 0.51 & 1.64 & 0.31 & 0.7598 \\
\hline \multirow{4}{*}{ Alemsaga } & Intercept & 528.65 & 29.78 & 17.75 & $5.39 \mathrm{E}-11$ \\
\hline & $\mathrm{RF}$ & -2.99 & 11.43 & -0.26 & 0.7972 \\
\hline & Min $\mathrm{T}$ & 6.84 & 4.86 & 1.41 & 0.1810 \\
\hline & $\operatorname{Max} \mathrm{T}$ & -3.48 & 1.71 & -2.03 & 0.0617 \\
\hline \multirow{4}{*}{ Tara Gedam } & Intercept & 558.21 & 37.98 & 14.70 & $6.67 \mathrm{E}-10$ \\
\hline & $\mathrm{RF}$ & 29.50 & 18.18 & 1.62 & 0.1269 \\
\hline & $\operatorname{Min} \mathrm{T}$ & 7.46 & 4.52 & 1.65 & 0.1206 \\
\hline & $\operatorname{Max} \mathrm{T}$ & -3.32 & 1.89 & -1.76 & 0.1007 \\
\hline
\end{tabular}

RF stands for rainfall, Min $T$ for minimum temperature, and Max $T$ for maximum temperature.

\section{Conclusion}

In this study, it was confirmed that butterfly diversity and abundance varied with habitat level of degradation. Vegetation type was one factor for the abundance and diversity of butterflies because there was higher abundance and diversity of butterflies in forest areas than in other habitats. Numbers and diversity were lower during the dry season. Abundance of butterflies was positively related with the amount of rainfall and minimum temperature and negatively with maximum temperature. Butterfly species must be regularly monitored and their habitats preserved for the health of the entire ecosystem.

\section{Data Availability}

Data are available from the corresponding author upon request.

\section{Disclosure}

The writing of this paper was the responsibility of the authors and the funder was not involved.

\section{Conflicts of Interest}

The authors declare no conflicts of interest.

\section{Acknowledgments}

The authors thank Bahir Dar University, Biology Department, Ethiopia, for partial financial support and laboratory services. The research fund was through a local scholarship fund by Bahir Dar University, Ethiopia.

\section{References}

[1] R. F. Noss, "A regional landscape approach to maintain diversity," BioScience, vol. 33, no. 11, pp. 700-706, 1983.

[2] M. G. Turner, R. V. O’Neill, R. H. Gardner, and B. T. Milne, "Effects of changing spatial scale on the analysis of landscape pattern," Landscape Ecology, vol. 3, no. 3-4, pp. 153-162, 1989.

[3] R. T. Forman, Land Mosaics: The Ecology of Landscapes and Regions, Cambridge University Press, Cambridge, UK, 1995.

[4] K. C. Kim, "Biodiversity, conservation and inventory: why insects matter," Biodiversity and Conservation, vol. 2, no. 3, pp. 191-214, 1993.

[5] M. J. Samways, Insect conservation biology, p. 358, Springer Netherlands, Dordrecht, Netherlands, 1994.

[6] C. D. Thomas and H. C. Mallorie, "Rarity, species richness and conservation: butterflies of the atlas mountains in Morocco," Biological Conservation, vol. 33, no. 2, pp. 95-117, 1985.

[7] E. Pollard and T. J. Yates, Monitoring Butterflies for Ecology and Conservation, Chapman \& Hall, London, UK, 1993.

[8] M. J. Scoble, The Lepidoptera: Form, Function and Diversity, p. 404, Oxford University Press, New York, NY, USA, 1992. 
[9] A. Erhardt, "Diurnal Lepidoptera: sensitive indicators of cultivated and abandoned grassland," Journal of Applied Ecology, vol. 22, no. 3, pp. 849-861, 1985.

[10] J. Leps and K. Spitzer, "Ecological determinants of butterfly communities (Lepidoptera, papilionidae) in the Tam Dao Mountains, Vietnam," Acta Entomologica Bohemoslovaca, vol. 87, pp. 182-194, 1990.

[11] K. Spitzer, J. Jarǒ̌, J. Havelka, and J. Lep̌̌, "Effect of smallscale disturbance on butterfly communities of an Indochinese montane rainforest," Biological Conservation, vol. 80, no. 1, pp. 9-15, 1997.

[12] J. M. Molina and J. M. Palma, "Butterfly diversity and rarity within selected habitats of western Andalusia, Spain (Lepidoptera: papilionoidea and Hesperioidea)," Nota Lepidopterologica, vol. 78, pp. 267-280, 1996.

[13] P. A. Wood and M. J. Samways, "Landscape element pattern and continuity of butterfly flight paths in an ecologically landscaped botanic garden, Natal, South Africa," Biological Conservation, vol. 58, pp. 149-166, 1992.

[14] C. Kremen, "Assessing the indicator properties of species assemblages for natural areas monitoring," Ecological Applications, vol. 2, no. 2, pp. 203-217, 1992.

[15] T. R. New, Butterfly Conservation, Oxford University Press, South Melbourne, Australia, 1991.

[16] T. R. New, R. M. Pyle, J. A. Thomas, C. D. Thomas, and P. C. Hammond, "Butterfly conservation management," Annual Review of Entomology, vol. 40, no. 1, pp. 57-83, 1995.

[17] A. B. Swengel, "Effects of fire and hay management on abundance of prairie butterflies," Biological Conservation, vol. 85, no. 2, pp. 73-85, 1996.

[18] R. B. Blair and A. E. Launer, "Butterfly diversity and human land use: species assemblages along an urban grandient," Biological Conservation, vol. 80, no. 1, pp. 113-125, 1997.

[19] D. Riepe and B. Toborg, "Butterflies and moths of national parks, state parks, and national wildlife refuges," Park Science, vol. 16, no. 4, pp. 15-18, 1996.

[20] J. Abaynew and G. Emana, "Diversity of butterfly communities at different altitudes of Menagesha-Suba state forest Ethiopia," Journal of Entomology and Zoology Studies, vol. 6, no. 2, pp. 2197-2202, 2018.

[21] B. Fenta, "Waste management in the case of Bahir dar city near Lake Tana shore in northwestern Ethiopia: a review," African Journal of Environmental Science and Technology, vol. 11, pp. 393-412, 2017.

[22] M. Worku, "The role of forest biodiversity conservation practices for tourism development in a case of Tara Gedam monastery, South gonder zone, Ethiopia," Journal of Ecosystem \& Ecography, vol. 7, no. 2, p. 231, 2017.

[23] ORDA, Participatory Alemsaga Forest Resources Assessment, Bahir Dar, Ethiopia, 2012.

[24] M. Getinet, S. Teshome, and K. Ensermu, "Status and species diversity of Alemsaga forest, northwestern Ethiopia," Advances in Life Science and Technology, vol. 34, pp. 87-100, 2015.

[25] N. Haregeweyn, G. Fikadu, A. Tsunekawa, M. Tsubo, and D. T. Meshesha, "The dynamics of urban expansion and its impacts on land use/land cover change and small-scale farmers living near the urban fringe: a case study of Bahir Dar, Ethiopia," Landscape and Urban Planning, vol. 106, no. 2, pp. 149-157, 2012.

[26] K. Kassie, "The problem of solid waste management and people awareness on appropriate solid waste disposal in Bahir Dar City: Amhara region, Ethiopia," Journal of Health and Environmental Sciences, vol. 3, pp. 1-8, 2016.
[27] E. Pollard, "A method for assessing changes in the abundance of butterflies," Biological Conservation, vol. 12, no. 2, pp. 115-134, 1977.

[28] S. Woodhall, Field Guide to Butterflies of South Africa, Struik Publishers, Cape town, South Africa, 2005.

[29] M. F. Braby, A Complete Field Guide to Butterflies of Australiap. 296, 2nd edition, CSIRO Publishing, Clayton, Australia, 2016.

[30] J. G. Williams, A Field Guide to the Butterflies of Africa, p. 238, Collins, London, UK, 1969.

[31] O. G. Gorbunov, "On the pierid butterflies of the West Shewa zone (Ethiopia) (Lepidoptera: Pieridae)," The Biological Society of Ethiopia, vol. 16, pp. 95-147, 2017.

[32] Ø. Hammer, D. A. T. Harper, and P. D. Ryan, "PAST: paleontological statistics software package for education and data analysis," Palaeontologia Electronica, vol. 4, no. 9, , 2001, http://palaeo-electronica.org/2001_1/past/issue1_01.htm.

[33] K. R. Clarke and R. M. Warwick, Changes in Marine Communities: An Approach to Statistical Analysis and Interpretation, PRIMER-E: Plymouth, Devon, England, 2nd edition, 2001.

[34] V. K. Chey, J. D. Holloway, and M. R. Speight, "Diversity of moths in forest plantations and natural forests in Sabah," Bulletin of Entomological Research, vol. 87, no. 4, pp. 371-385, 1997.

[35] C. J. Krebs, Ecological Methodology, p. 654, Harper and Row Publishers Inc., New York, NY, USA, 1989.

[36] N. McAleece, Biodiversity professional beta, The National History Museum and The Scottish Association for Marine Science, 1998.

[37] B. D’Aniello, I. Stanislao, S. Bonelli et al., "Haying and grazing effects on the butterfly communities of two Mediterranean area grasslands," Biodiversity and Conservation, vol. 20, pp. 1731-1744, 2011.

[38] O. Norfolk, A. Asale, T. Temesgen et al., "Diversity and composition of tropical butterflies along an Afromontane agricultural gradient in the Jimma Highlands, Ethiopia," Biotropica, vol. 49, no. 3, pp. 346-354, 2017.

[39] A. Jemal and E. Getu, "Diversity of butterfly communities at different altitudes of Menagesha-suba state forest, Ethiopia," Journal of Entomology and Zoology Studies, vol. 6, no. 2, pp. 2197-2202, 2018.

[40] R. Koneri and P. V. Maabuat, "Diversity of butterflies (Lepidoptera) in manembo-nembo wildlife Reserve, north sulawesi, Indonesia," Pakistan Journal of Biological Sciences, vol. 19, no. 5, pp. 202-210, 2016.

[41] V. Fileccia, S. Santorsola, S. Arpaia et al., "Seasonal patterns in butterfly abundance and species diversity in five characteristic habitats in sites of community importance in Sicily (Italy)," Bulletin of Insectology, vol. 68, no. 1, pp. 91-102, 2015.

[42] K.-O. Bergman, J. Dániel-Ferreira, P. Milberg, E. Öckinger, and L. Westerberg, "Butterflies in Swedish grasslands benefit from forest and respond to landscape composition at different spatial scales," Landscape Ecology, vol. 33, no. 12, pp. 2189-2204, 2018.

[43] A. Abiodun, J. Kehinde, and G. Samuel, "Butterfly species diversity and abundance in University of Ibadan botanical garden, Nigeria," Open Journal of Ecology, vol. 5, pp. 352-360, 2015. 